\title{
An Empirical Analysis of Adult Obesity in West Virginia
}

\author{
J. Herath and T. Gebremedhin *
}

\begin{abstract}
West Virginia reports the highest obesity level in the United States. Every 3 in 10 adults are obese, and the prevalence of obesity is nearly 8\% higher than the national level. Obesity is linked with several diseases such as heart disease, diabetes II, hypertension, cancer, arthritis, asthma, and some psychological disorders. The reported economic burden associated with obesity is considerably high. This research study attempts to examine the use of exercise and cutting down of calorie intakes in controlling obesity in West Virginia using the 2009 Behavioral Risk Factor Surveillance System data. Three logit models were estimated. Furthermore, results indicate that obese adults are less likely to engage in exercises to lose weight compared to nonobese adults. Among obese individuals only 15\% cut down calorie intakes to lose weight where as the respective proportion from the entire population is $31 \%$. Low income levels, and presence of diseases such as diabetes, hypertension, arthritis, and asthma, have positive effects on obesity in West Virginia. Obesity can significantly be alleviated through physical activities in West Virginia.
\end{abstract}

\section{Introduction}

Obesity is a major health problem in the United States. Approximately $34 \%$ of the U.S. adult population is obese, which is over 72 million people (Finkelstein et al., 2009). The studies of Behavior Risk Factor Surveillance Systems (BRFSS), and the National Health and Nutritional Examination Survey (NHANES) show that obesity in the United States will increase from its current level of $31.3 \%$ to $42.8 \%$ in 2018 . According to Dor et al. (2010), if the current trend of obesity continues, $50 \%$ of the U.S. population will be obese in 2030.

Obesity is linked with several diseases such as heart disease, diabetes II, hypertension, cancer, arthritis, asthma, and some psychological disorders (Malnick and Knobler, 2006). Obesity increases the risk of premature mortality (WHO, 2005) and nearly 300,000 annual deaths are associated with

\footnotetext{
* Authors are, respectively, Graduate Research Assistant and Professor, Division of Resource Management, Davis College of Agriculture, Natural Resources and Design, West Virginia University, Morgantown, USA.
} 
obesity in the United States (Miljkovic and Nganje, 2008). With the exception of increasing risk of diseases and disability, obesity degrades the quality of life by limiting mobility, physical endurance, social, academic and job participation (Scinanama et al., 2000). The reported economic burden associated with obesity is high. According to the U.S. Department of Health and Human Services (2010), the annual cost of obesity was $\$ 147$ billion in the year 2008 and people who were obese had medical costs that were $\$ 1,429$ higher than the cost for people of normal body weight. Present, the overall annual cost of being obese is $\$ 2,646$ for an obese man and $\$ 4,879$ for an obese woman (Dor et al., 2010).

Obesity can be controlled in different ways and physical activity or exercise is one of them. For instance, a sustained $10 \%$ weight loss reduces an overweight person's lifetime medical costs by $\$ 2,200$ to $\$ 5,300$ by lowering costs associated health diseases (Center for Disease Control and Prevention (CDC), 2007). Nearly $\$ 77$ billion direct medical cost can be prevented annually by increasing regular exercises among the inactive Americans (about 88 million) over age 15 years (Pratt et al., 2000). Studies indicate that aspects of the home, school, work and community environments all influence physical activity levels of an individual (Natalie et al., 2010). According to U.S Department of Health and Services (2007), women are less active than men, and African-Americans, Hispanics and individuals of lower income status are also less engage in exercise. Many states are addressing physical activity issues with statewide action plans, interagency cooperation efforts and health department initiatives. In a study conducted at the University of Pittsburgh from 2007 to 2010 with 130 severely obese adult participants without diabetes, Goodpaster et al. (2010) showed that people in obesity class II and III can reduce their weight through lifestyle change and moderateintensity physical activity.

In overcoming severe obesity, diet, exercise, and behavioral modifications are recommended which result in 5\% to $10 \%$ weight loss in the short term (Natalie et al., 2010). A health study in 2002 across the United States and Canada showed that vegetarian diets provide higher protection against overweight (Sabate and Wein, 2010). Culter et al. (2003) revealed that higher consumption of calories outside the main meals positively affects obesity. Among the major causal factors of obesity is a positive balance of calories (Rosin, 2008). Also, sedentary lifestyles and high-fat energy-dense diets are the fundamental causes of obesity (Anderson and Butcher, 2006a).

Education and schooling play a major role in obesity. Higher education lowers obesity rates as health promotion occurs through knowledge (Nayga, 2000). Cawley et al. (2005) showed that the impact of decreased physical education (PE) classes in schools on youth, increased the probability 
of students' overweight. According to Kumanyika et al. (2008) higher prevalence of obesity is reported from rural areas compared to urban areas. Kahn et al. (1998) argued that the rural obesity may relate with local poverty and lack of resources, especially in certain pockets of rural areas. Smoking cigarettes is associated with some obesity related diseases like cancer and heart diseases.

The use of exercise and control of calorie intake in weight gain control is already identified. However, the potential use of them vary from state to state. Thus, the main objective of this study is to examine the potential use of exercise and fewer calorie intake in controlling obesity in West Virginia, which reports high rates of obesity in U.S. The results will assist in achieving applicable policy interventions in healthcare development in West Virginia.

The paper is organized into five sections. Section 2 provides background of the study area. Section 3 covers the methodology and data sources. Section 4 discusses the empirical results and analysis. Section 5 presents the conclusions and policy implications.

\section{Background of the Study Area}

West Virginia is in the Appalachian and northeastern regions. The total population of West Virginia is about 1.85 million of which nearly $56 \%$ live in urban areas while the rest live in rural areas (U.S. Census Bureau, 2011). Nearly $79 \%$ of the population is adults and $51 \%$ of the total population is female. Of the total population $94 \%$ are white while $3.4 \%$ are African Americans. West Virginia reported the $5^{\text {th }}$ highest poverty rate, $17.4 \%$ in year 2008 (ARC, 2008) and at present, the rural poverty rate is $19.9 \%$, which is a little higher than the urban poverty rate. The annual per capita personal income was $\$ 32,219$ in 2009 , which was $17.7 \%$ below the national per capita income of $\$ 39,138$ (Hammond, 2011). The per capita income is low in the rural areas compared to the urban areas.

West Virginia reports the highest obesity level in the United States, which is $33.5 \%$ (Gallup, 2011). Every 3 in 10 adults are obese in West Virginia and the prevalence of obesity is nearly $8 \%$ higher than the average rates (Gallup, 2011). According to CDC (2007) of the adults, 30\% were considered as obese in 2007. Importantly, CDC explained that the problem is related with other obesity related factors like, no leisure time physical activity, less consumption of fruits and vegetables, and more consumption of soda, and other chronic diseases. Education, availability of food stores, commuting time, annual wage and built environment are significant factors that affect obesity in West Virginia (Amarasinghe et al., 2006). Obesity affects the 
4

economy of West Virginia, and for instance, medical cost associated with adult obesity was 500 million dollars in 2003 (CDC, 2007).

\section{Methodology}

In a consumer's utility maximization context, Becker (1965) and Lancaster (1966) used household production models where desirable attributes were created from market goods and household labor, subject to budget and time constraints. In 1972, Grossman extended this framework in a health context to derive the demand for the commodity 'good health,' a desirable attribute that is produced by an individual and enters into the individual's utility function. Investments in healthcare or conditions for good health can be explained by a household's production function. The time of the consumer and market goods such as medical care, diet, exercise, recreation, and housing as well as exogenous or given socioeconomic and demographic characteristics are combined (Grossman, 1972) to create good health.

Obesity can be assumed as a function of an individual's energy balance which is the difference between calorie intakes and expenditure for a particular time period. In the context of Becker's (1965) household production theory of consumer behavior, obesity can be considered as the byproduct of other goals of an individual's utility function (Chou et al., 2004). Thus, Becker provides a framework for examining the issues of calorie intake and expenditure with the recognition of a rational consumer that uses goods and services purchased in the market, together with his/her own time to produce more commodities that enter his/her utility function. Health is one of these commodities that depend partly on the consumption of appropriate diet and engaging in physical activities or exercise in the intention of weight gain control.

Thus, to control weight gain an individual can reduce calorie consumption and/or can engage in physical activities. Because of the interdependence of caloric intake, physical activity, and obesity, a set of three simultaneous equations are used for the analysis (equation 1 to 3 ). The first dependent variable, $\mathrm{C}_{\mathrm{i}}$, reflects the decision of individual $i$ to reduce his/her caloric intake, which appears as a binary choice, where $C_{i}$ is equal to 1 , if individual $\mathrm{i}$ has decided to reduce calories and equal to zero otherwise. The second dependent variable $\mathrm{PA}_{\mathrm{i}}$, represents whether an individual $i$, engages in exercise (physical activity) or not. If the individual engages in exercise (except what $\mathrm{s} /$ he does in his/her normal job) $\mathrm{PA}_{\mathrm{i}}$ equals to 1 or otherwise 0. The third dependent variable, $\mathrm{O}_{\mathrm{i}}$ is whether an individual $i$ is obese or not and if obese $\mathrm{O}_{\mathrm{i}}$ equals to 1 , otherwise 0 . Independent variable $\mathrm{D}_{\mathrm{ji}}$ represents the $\mathrm{j}^{\text {th }}$ disease of the $\mathrm{i}^{\text {th }}$ individual, which appears as a qualitative variable equal to 1 if the individual has the disease and 0 otherwise. Disease $j$ goes from 1 to 6 
5

for asthma, hypertension, heart disease, arthritis, diabetics, and cancer. $\mathrm{SF}_{\mathrm{i}}$, $\mathrm{BF}_{\mathrm{i}}$, and $\mathrm{EF}_{\mathrm{i}}$ are socioeconomic factors, other behavioral factors, and environmental factors respectively which are specified for each individual.

$\mathrm{C}_{\mathrm{i}}=\mathrm{f}\left(\mathrm{O}_{\mathrm{i}}, \mathrm{PA}_{\mathrm{i}}, \mathrm{D}_{\mathrm{ji}}, \mathrm{SF}_{\mathrm{i}}, \mathrm{EF}_{\mathrm{i}}, \mathrm{BF}_{\mathrm{i}}\right)$

$\mathrm{PA}_{\mathrm{i}}=\mathrm{g}\left(\mathrm{O}_{\mathrm{i}}, \mathrm{C}_{\mathrm{i}}, \mathrm{D}_{\mathrm{ji}}, \mathrm{SF}_{\mathrm{i}}, \mathrm{EF}_{\mathrm{i}}, \mathrm{BF}_{\mathrm{i}}\right)$

$\mathrm{O}_{\mathrm{i}}=\mathrm{h}\left(\mathrm{C}_{\mathrm{i}}, \mathrm{PA}_{\mathrm{i}}, \mathrm{D}_{\mathrm{ji}}, \mathrm{SF}_{\mathrm{i}}, \mathrm{EF}_{\mathrm{i}}, \mathrm{BF}_{\mathrm{i}}\right)$,

\section{Types and Sources of Data}

Behavior Risk Factor Surveillance Systems (BRFSS) survey data for the year 2009 was mainly used for the analysis. BRFSS is a survey of health risk behaviors in non-institutionalized civilian adults, age 18 years and over. These data were collected from a stratified random sample through computerassisted telephone interviewing by state health departments with the collaboration of the Center for Disease Control and Prevention. Interviewers were given an additional training on BRFSS questionnaire and procedures before the work. Also, interviewers were systematically monitored a certain amount of time each month. Interviews were conducted during each calendar month at week days, weekends, day time as well as evenings following the standard procedures of an interview.

Data on obesity, diseases, socioeconomic factors (income, age, family size, gender, race, marital status, education, healthcare insurance), and behavioral factors (smoke, consume alcohol, engage in physical activities or exercise, calorie intake, sleepless days were mainly collected from BRFSS data 2009 for analysis. Missing data reported on height and weight, income, sex, diseases, and other variables with data on reported pregnant women, were not considered for the analysis. Statistical software of STATA 9.0 was used for logistic analysis.

\section{Empirical Results and Discussion}

\section{Descriptive Analysis}

The descriptions of the variables with their mean values and standard deviations are presented in Table 1 . According to the results nearly $31 \%$ of the individuals in the whole sample are obese in West Virginia. Of the total sample $63 \%$ of the individuals engage in physical activities and $31 \%$ eat fewer calories in controlling weight gain and related health implications. Interestingly, $42 \%$ of the individuals in the sample are female with an average age of 55 years. Nearly $96 \%$ of the sample consists of white Americans and the majority of them live in urban areas. About $85 \%$ of the individuals in the sample have at least up to high school. The annual average income of 
$\$ 27,140.00$ indicates that most of the population is medium or low income earners. Approximately $23 \%$ of individuals of the sample smoke cigarettes while $37 \%$ of them are engaged in alcohol consumption. Considering health problems, $44 \%$ of the individuals indicate hypertension while $41 \%$ show some sort of arthritis. The presence of individuals having diabetes, heart diseases, asthma, and cancer are $15 \%, 13 \%, 11 \%$ and $13 \%$, respectively, in the whole sample.

Table 1: Description and means of the variables

\begin{tabular}{llrr}
\hline Variable & Description & Mean & Std. Dev. \\
\hline Obesity & 1 if obese; 0 otherwise & $\mathbf{0 . 3 0 6}$ & 0.461 \\
Exercise & 1 if engage in physical exercise; 0 otherwise & $\mathbf{0 . 6 3 3}$ & 0.481 \\
& in last 30 days & $\mathbf{0 . 3 1 3}$ & 0.464 \\
Calorie intake & 1 if reduce calorie intake; 0 otherwise & 0.383 & 0.486 \\
Sex & 1 if male; 0 otherwise & 55.234 & 17.153 \\
Age & In years & 0.855 & 0.352 \\
Edu & 1 if learned up to high school or more than & & 0.966 \\
& high school; 0 otherwise & 0.536 & 0.178 \\
Race & 1 if white; 0 otherwise & $27,141.890$ & $25,665.440$ \\
MSA & 1 if in an urban area; 0 otherwise & 0.225 & 0.4179 \\
Income & Annual income in dollars & 0.369 & 0.482 \\
Smoke & 1 if smokes; 0 otherwise & 0.156 & 0.363 \\
Alcohol & 1 if take alcohol; 0 otherwise & 0.442 & 0.496 \\
Diabetes & 1 if diabetic; 0 otherwise & 0.134 & 0.341 \\
Hypertension & 1if hypertension; 0 otherwise & 0.119 & 0.324 \\
Heart Diseases & 1 if heart diseases; 0 otherwise & 0.1393 & 0.346 \\
Asthma & 1 if suffers from asthma; 0 otherwise & 0.415 & 0.492 \\
Cancer & 1 if suffers from a cancer; 0 otherwise & 9.457 & 11.273 \\
Arthritics & 1 if suffers from Arthritics; otherwise & & \\
Sleepless & Days of sleepless in the previous month & & \\
\hline
\end{tabular}

\section{Logit Analysis}

The logit estimations for obesity, exercise, and calorie intake variables are presented in Tables 2, 3 and 4. Marginal effects of each estimation $(\mathrm{dy} / \mathrm{dx})$, standard errors, and p-values are shown in the Tables.

According to Table 2 most of the variables are statistically significant with the expected signs. The negative sign of exercise indicates that individuals who are more likely to engage in exercise are less likely to be obese, i.e. an adult engages in exercise is $0.1(10 \%)$ times less likely of getting obese. Age and annual income indicate nonlinear effects on obesity. Smokers are less likely to become obese compared to others. However, literature is limited related to the link of obesity and smoking and according to Peters et al. (2003) the increase in health risks when smoking and obesity combined are not widely understood. Even though alcohol consumption is assumed to be a risk factor for obesity (Wang et al., 2010) empirical results do not support the argument. Individuals suffering from diabetes, asthma and arthritics are more likely to become obese than healthy individuals. For instance, if an adult individual is suffering from diabetes, $\mathrm{s} /$ he is 0.20 times 
(20\%) more likely of getting obese while an adult suffering from asthma or arthritics it is $10 \%$ more likely of getting obese in West Virginia. Suffering from cancer does not indicate any significant relation with obesity. Even though the relationship between obesity and hypertension is plausible (Kotchen, 2008), results indicate that hypertension is positively related with obesity in West Virginia i.e. an adult suffering from hypertension has a $20 \%$ more chance of getting obese than an adult of non-hypertension. Significant results of number of sleepless days indicate that obesity is associated with inadequate sleep. The result is supported by Gangwisch et al. (2005), explained that sleep deprivation could play a significant role in the discussion of obesity in some individuals. Education up to high school or more does not indicate a clear impact on obesity reduction in the sampled population, even though the reduction of obesity with more education was proved true in many studies (Nayga, 2000; Drewnowski and Specter, 2004; Cawley et al., 2005).

Table 2: Logit regression results: marginal effects for obesity

\begin{tabular}{lcrr}
\hline Variable & \multicolumn{1}{c}{$\mathbf{d y} / \mathbf{d x}$} & Std. Err. & $\mathbf{P}>|\mathbf{z}|$ \\
\hline Exercise & $-0.0983^{* * *}$ & 0.015 & 0.000 \\
Age $_{\text {Age }^{2}}$ & $0.0148^{* * *}$ & 0.002 & 0.000 \\
Income $_{\text {Income }}$ & $-0.0002^{* * *}$ & 0.000 & 0.000 \\
Smoke & $2.4 \mathrm{e}-06^{* *}$ & 0.000 & 0.046 \\
Alcohol & $-2.4 \mathrm{e}-11^{* *}$ & 0.000 & 0.058 \\
Diabetes & $-0.1081^{* * *}$ & 0.015 & 0.000 \\
Hypertension & 0.0126 & 0.015 & 0.400 \\
Asthma & $0.2004^{* * *}$ & 0.021 & 0.000 \\
Arthritics & $0.1702^{* * *}$ & 0.015 & 0.000 \\
Sleepless & $0.0943^{* * *}$ & 0.022 & 0.000 \\
Cancer & $0.1038^{* * *}$ & 0.015 & 0.000 \\
Race & $0.0018^{* * *}$ & 0.000 & 0.004 \\
Edu & 0.0219 & 0.021 & 0.296 \\
\hline $\mathrm{N}=4,757 ;$ LR chi2(15) & $-\mathbf{6 3 1 . 1 4} ;$ Prob $>$ chi2 $=0.0000 ;$ & 0.477 \\
$\mathbf{0 . 1 0 7 6} ;$ Log likelihood $=\mathbf{- 2 6 1 7 . 6 4 9}$ & 0.039 & 0.485 \\
\hline
\end{tabular}

$* * *, * *, *$ are significant at $\%, 5 \%$ and $10 \%$ respectively 
8

Table 3: Logit regression results: marginal effects for exercise

\begin{tabular}{lcrr}
\hline Variable & dy/dx & Std. Err. & $\mathbf{P}>|\mathbf{z}|$ \\
\hline Obesity & $-0.1045^{* * *}$ & 0.016 & 0.000 \\
Calorie intake & $0.0835^{* * *}$ & 0.022 & 0.000 \\
Age & $-0.0041^{* * *}$ & 0.000 & 0.000 \\
Income & $2.5 \mathrm{e}-6 * * *$ & 0.000 & 0.000 \\
Edu & $0.1221 * * *$ & 0.022 & 0.000 \\
Smoke & $-0.1023 * * *$ & 0.018 & 0.000 \\
Alcohol & -0.0077 & 0.015 & 0.625 \\
Diabetes & $-0.0732 * * *$ & 0.021 & 0.001 \\
Hypertension & $-0.0662 * * *$ & 0.023 & 0.004 \\
Asthma & -0.0261 & 0.022 & 0.253 \\
Cancer & 0.0042 & 0.021 & 0.839 \\
Arthritics & -0.0244 & 0.016 & 0.127 \\
Sleepless & $-0.0038 * * *$ & 0.001 & 0.000 \\
MSA & $0.0241 *$ & 0.014 & 0.097 \\
Race & 0.0074 & 0.041 & 0.857 \\
\hline N = 4,757; Prob $>$ chi2 & $=0.0000 ;$ Log likelihood $=\mathbf{2 8 8 8 . 1 1 ;}$ & \\
LR chi2(15) = 469.12; Pseudo R ${ }^{2}=\mathbf{0 . 0 7 5 1}$ & & \\
\hline$* * * * * *$ are significant at $\%, 5 \%$ and $10 \%$ respectively &
\end{tabular}

Logit analysis for exercise is given in Table 3. Results indicate that obese individuals are less likely to engage in exercise in losing weight gain compared to the non-obese individuals. According to Table 3, an obese adult is 0.10 times $(10 \%)$ less likely of engaging in exercise which is useful in controlling weight gain. This implies the challenge of promoting obese individuals towards engaging in exercise for weight gain control. Table 3 further indicates that those who decide to take fewer calories are more likely to engage in physical activities for weight reduction. As expected, age indicates a negative relationship with exercise. However, this may be different with the retired individuals who get more time for exercise. Education indicates a positive relationship with exercise and adults educated more than high school level, are $12 \%$ more likely to engage in exercise for weight gain control. Increasing annual household income also indicates the potential of more exercise of individuals. This may be with high potential of accessing exercise centers. Smokers seemed to be less likely to engage in exercise. Result is supported by the study of Conway and Cronan (1993) that explains the smokers' less potential of engaging in exercise. Alcohol consumers show insignificant relationship with exercise. Individuals suffering from diabetes, asthma, and hypertension are less likely to engage in physical exercise. The higher the number of sleepless days indicates the less potential of doing exercise too. Interestingly, individuals living in urban areas are more likely to 
9

exercise, may be due to more access of those exercising centers. Race does not show any significant relation with exercise.

Table 4 is the Logit regression results for calorie intakes. Results show that obese individuals in West Virginia are $15 \%$ ( 0.15 times) more likely to have fewer calorie intake. Individuals engage in physical activities are more likely to have fewer calorie intake. Increasing age seems to be reducing calorie intake as expected. Increasing income is associated with reduced caloric intake. However, marginal effect of income is very low (Table 4). Alcohol consumption indicates a positive impact on fewer calorie intake, may be with higher alcohol consumption reduces food consumption (Yeomans et al., 2003). As expected individuals who report arthritics, heart diseases, and diabetes are more likely to take fewer calories. Education, cancer, asthma, sleepless day, and race do not indicate significant relations with fewer calorie intake.

Table 4: Logit regression results: marginal effects for calorie intake

\begin{tabular}{lcrr}
\hline Variable & $\mathbf{d y} / \mathbf{d x}$ & Std. Err. & $\mathbf{P}>|\mathbf{z}|$ \\
\hline Obesity & $0.1478^{* * *}$ & 0.016 & 0.000 \\
Exercise & $0.0368^{* * *}$ & 0.014 & 0.013 \\
Age & $0.0041^{* * *}$ & 0.000 & 0.000 \\
Edu & -0.0017 & 0.020 & 0.929 \\
Income & $-6.7 \mathrm{e}-07^{* *}$ & 0.000 & 0.026 \\
Smoking & -0.0266 & 0.017 & 0.131 \\
Alcohol & $0.1855^{* * *}$ & 0.014 & 0.000 \\
Diabetes & $0.1467^{* * *}$ & 0.021 & 0.000 \\
Heart Diseases & $0.1115^{* * *}$ & 0.022 & 0.000 \\
Arthritics & $0.0607^{* * *}$ & 0.015 & 0.000 \\
Asthma & 0.0177 & 0.022 & 0.420 \\
Cancer & -0.0287 & 0.018 & 0.128 \\
Sleepless & -0.0001 & 0.001 & 0.790 \\
Race & $-0.0750^{*}$ & 0.042 & 0.078 \\
\hline N $=4,757 ;$ LR chi2 $(14)=\mathbf{7 5 1 . 2 1 ; ~ P r o b ~}>$ chi2 $=\mathbf{0 . 0 0 0 0} ;$ Pseudo $\mathbf{R}^{2}=\mathbf{0 . 1 2 6 5} ;$ \\
Log likelihood $=\mathbf{- 2 5 9 3 . 2 7 3 4}$ & & &
\end{tabular}

$* * *, * *, *$ are significant $@ 1 \%, 5 \%$ and 10\% respectively

\section{Conclusions and Policy Implications}

The paper investigated the relationship among obesity, exercise, and calorie intake of West Virginians using three simple Logit models. A few results stand out. The first result suggests the significant effects of exercise, and calorie intake in controlling weight gain or obesity in West Virginia. The study reveals the potential of $10 \%$ reduction of obesity through exercises or physical activities in West Virginia. Results also reveal that obese adults are less likely to engage in exercise too. Mean values (Table 1) of the study show 
that only $63 \%$ of the population engages in physical activities and $30 \%$ of the population is obese. Thus, facilitation of recreational centers, gyms, trails and other physical centers are essential to promote more exercises to decrease obesity which leads for premature mortality, morbidity, economic loss, and loss of life-standard quality in West Virginia.

The second important result is that low-income individuals are less likely to reduce calorie intake and engage in exercise. The study reveals that obese people are $15 \%$ more likely to fewer calorie intake, and adults that less calorie intake are more likely to have exercise. Mean value (Table 1) indicates that only $31 \%$ of the population like in less calorie intake to reduce obesity. Thus, implementation of more educational programs and promotions for fewer calorie intake are important to weight gain control in West Virginia, in the long run. As the low income levels have positive effects on increasing obesity and more calorie intake with low quality diets, generating effective income opportunities is essential, especially in the rural counties of West Virginia.

The other finding is that diabetes, hypertension, asthma, and arthritics are significantly related with obesity in West Virginia. Individuals suffering from diabetes, hypertension, arthritis, and asthma indicate $10 \%$ to $20 \%$ more likely of getting obese. Also, those who suffer from these diseases are less likely to engage in physical activities. This suggests the need of adequate healthcare polices to mitigate health diseases which control weight gain subsequently.

\section{References}

Amarasinghe, A., C. Brown, D'Souza and H. Oh (2006). The Impact of County Level Factors on Obesity in West Virginia, Research Paper 12, viewed $12^{\text {th }}$ September 2011, <www.rri.wvu.edu> .

Anderson, P.M. and K.F. Butcher (2006a). Childhood Obesity: Trends and Potential Causes. The Future of Children, 16(1):19-45.

Appalachian Regional Commission (2008). Viewed $21^{\text {st }}$ September, 2011, $<$ www.arc.gov $>$.

Becker, G. (1965). A Theory of Allocation of Time. The Economic Journal, 75:493-517.

Cawley, J., C. Meyerhoefer and D. Newhouse (2005). The Impacts of State Physical Education Requirements on Youth Physical Activity and Overweight. NBER Working Paper 11411. 
CDC (2007). Overweight and Obesity, viewed $10^{\text {th }}$ September, 2011, $<$ http://www.cdc.gov/obesity/stateprograms/fundedstates/west_virgini a.html >

CDC. (2007). Preventing Chronic Diseases: Investing Wisely in Health, Preventing Obesity and Chronic Diseases through Good Nutrition and Physical Activity, viewed $5^{\text {th }}$ December, 2011, $<$ http://www.cdc.gov/nccdphp/publications/factsheets/Prevention/obe sity.htm>

Chou, S., M. Grossman and H. Saffer (2004). An Economic Analysis of Adult Obesity: Results from the Behavioral Risk Factor Surveillance System, Journal of Health Economics, 23:565-587.

Conway, T.A. and Cornan, T.A (1993). Smoking, Exercise, and Physical Fitness. AD-AD234 658, Report no 90 43, Naval Medical Research and Development Command, Bethesda, Maryland. Viewed $10^{\text {th }}$ January, 2012, $\quad<$ http://www.dtic.mil/cgibin/GetTRDoc?AD=ADA234658>

Culter, D.M. E.L. Glaeser and J.M. Shapiro (2003). Why have Americans Become More Obese? Journal of Economic Perspectives, 17: 93-108.

Dor, A., C. Ferguson, C. Langwith and E. Tan (2010). A Heavy Burden: The Individual Costs of being Overweight and Obese on the United States. Research Report, Department of Health Policy, School of Public Health and Health Services, The George Washington University.

Drewnowski, A. and S. Specter (2004). Poverty and Obesity: The Role of Energy Density and Energy Costs. American Journal of Clinical Nutrition, 79:6-16.

Finkelstein, E., J. Trogdon, J.W. Cohen and W. Dietz (2009). Annual Medical Spending Attributable to Obesity: Payer-and Service -Specific Estimates. Health Affairs, 28(5):822-831.

Gallup (2011). Obesity Lowest in Colorado, Highest in West Virginia, viewed $15^{\text {th }}$ November, 2011, <www.gallup.com/poll/146534/obesity lowest-colorado-highest-west-virginia.asp $\mathrm{x}>$.

Gangwisch, J.E, D. Malaspina, B. Boden-Albala and S.B. Heymsfield (2005). Inadequate Sleep as a Risk Factor for Obesity: Analyses of the NHANES I. SLEEP, 28(10):1289-1296. 
Goodpaster, B.H., J.P. Delany, A.D. Otto, L. Kuller, J. Vockley, J.E. SouthPaul, S.B. Thomas, J. Brown, K. McTigue, K.C. Hames, W. Lang and J.M. Jakicic (2010). Effects of Diet and Physical Activity Interventions on Weight Loss and Cardio Metabolic Risk Factor in Severely Obese Adults: A Randomized Trial. Journal of the American Medical Association, 304(16):1795-1802.

Grossman, M. (1972). On the concept of health capital and the demand for health. The Journal of Political Economy, 80, 223-253.

Hammond, G.W. (2011). West Virginia Economic Outlook 2011. The Bureau of Business and Economic, College of Business and Economics, West Virginia University.

Kahn, H.S., L.M. Tatham, E. R. Pamuk and C.W. Heath (1998). Are Geographic Region with High Income Inequality Associated with Risk of Abdominal Weight Gain? Social Science and Medicine., 47:116.

Kotchen, T.A. (2008). Obesity-Related Hypertension? Weighing the Evidence. Hypertension, 52:801.

Kumanyika, S.K., E. Obarzanek, N. Stettler, R. Bell, A.E. Field, S.P. Formann, B.A. Franklin, M.W. Gillman, C.E. Lewis, W.C. Poston, J. Steven and Y. Hong (2008). Population-based Prevention of Obesity: The Need for Comprehensive Promotion of Health Eating, Physical Activity, and Energy Balance: A Scientific Statement from American Heart Association Council on Epidemiology and Prevention, Interdisciplinary Committee for Prevention. Circulation, 118:428464.

Lancaster, K. (1966). A new approach to consumer theory. The Journal of Political Economy, 74, 132-157.

Malnick, S.D.H. and H. Knobler (2006). The Medical Complications of Obesity, Quarterly Journal of Medicine, 99(9):565-579. Doi:10.1093/qjmed/hc1085.

Miljkovic, D. and W. Nganje (2008). Regional Obesity Determinants in the United States: A Model of Myopic Addictive Behavior in Food Consumption, Agricultural Economics, 38:375-384.

Nataile, S.T., C. Suchindran, K.E. North, B.M. Popkin and P.G. Larsen (2010). Association of Adolescent Obesity with Risk of Severe 
Obesity in Adulthood. Journal of the American Medical Association, 304(18):2042-2047.

Nayga, R.M. (2000). Schooling, Health Knowledge and Obesity, Applied Economics, 32:815-822.

NHANES Surveys (1980-2008). Viewed $15^{\text {th }}$ July, 2011, $<$ http://www.cdc.gov/nchs/nhanes.htm $>$

Peters, A., J. J. Barendregt, F. Willekens, J.P. Mackenbach, A. Al Mamun, and L. Bonneux (2003). Obesity in Adulthood and its Consequences for Life Expectancy: A Life-table Analysis. Ann Intern Med., 7:24-32.

Pratt M, C.A. Macera and G. Wang (2000). Higher Direct Medical Costs Associated with Physical Inactivity. The Physician and Sports Medicine, 28:63-70.

Rosin, O. (2008). The Economic Causes of Obesity: A Survey, Journal of Economic Surveys, 22(4):617-647.

Sabate, J. and M. Wien (2010). Vegetarian Diets and Childhood Obesity Prevention. American Journal of Clinical Nutrition, 9(suppl): 15251529.

Sciamanna, C.N., D.F., Land, W., and R.R. Wing (2000). Who Reports Receiving Advice to Lose Weight: Results from a Multistate Study. Archive of Internal Medicine, 160(15):2334-2339.

STATA 9.0. Statistical/Data Analysis. <http://www.stata.com>

U.S. Census Bureau. (2011). State and County Quick Facts, viewed $16^{\text {th }}$ September, 2011, <http://quickfacts.census.gov/qfd/ states/54000.html>

U.S. Department of Health \& Human Services. (2007). Healthy People 2010: Leading Health Indicators, viewed $2^{\text {nd }}$ December, 2011, $<$ http://www.healthpeople.gov/Document/html/uih/uih_4.htm>.

U.S. Department of Health and Services (2010). The Surgeon General Call to Action to Prevent and Decrease Overweight and Obesity. Rockville, MD: U.S. Department of Health and Human Services, Office of Surgeon General. 
14

Wang, L.U., I.M. Lee, J.E. Manson, J.E. Buring and H.D. Sesso (2010). Alcohol Consumption, Weight Gain, and Risk of Becoming Overweight in Middle-aged and Older Women. Arch Intern Med, 170(5):453-461.

World Health Organization (2005). Overweight and Obesity. Risk Factor Projects, viewed $15^{\text {th }} \quad$ November, 2011, $<$ http://www.who.int/mediacentre/news/releases/2005/pr44/en/index. html>

Yeomans M. R, S. Caton, and M.M. Hetherington (2003). Alcohol and Food intake. MM. Current Opinion in Clinical Nutrition and Metabolic Care, 6(6):639-644. 